\title{
Effect of Salinity on Biochemical Traits and Photosynthesis-Related Gene Transcription in Chlorella vulgaris
}

\author{
R. Kebeish", Y. El-Ayouty and A. Hussein \\ Botany and Microbiology Department, Plant Biotechnology \\ Laboratory, Facaulty of Science, Zagazig University, 44519 \\ Zagazig, Egypt.
}

\begin{abstract}
7 HIS STUDY was conducted to investigate the effect of $\mathrm{NaCl}$ on the physiological and biochemical traits of Chlorella vulgaris. The Alga was exposed to different concentrations of $\mathrm{NaCl}$ ranging from 50-300 mM besides control over a period of 10-20 days. Total chlorophyll contents and carotenoids levels were increased at low $\mathrm{NaCl}$ concentrations but significantly reduced at higher concentrations. It is interesting to note that total free amino acids and proline contents increased at low and moderate $\mathrm{NaCl}$ concentrations. The activity of the antioxidant enzymes; CAT, POD, PPO, and SOD; were noticeably increased by increasing salt concentration up to $200 \mathrm{mM}$ and thereafter declined. The photosynthetic related genes expression; $r b c \mathrm{~L}, p s a \mathrm{~B}$, and $p s b \mathrm{C}$; were significantly reduced at all $\mathrm{NaCl}$ concentrations. The results indicated that salt stress inhibits PSII efficiency and reduces the overall $\mathrm{CO}_{2}$ assimilation rate in Chlorella vulgaris
\end{abstract}

Keywords: Chlorella vulgaris, Salinity, Pigment fraction, Antioxidant enzymes, Photosynthetic genes transcript

Algae are one of the most variable organisms that play a principal role for food production (Britton et al., 1995; Takaichi, 2011). Chlorella is one of the eukaryotic unicellular green microalgae belongs to Chlorophyta. It contains green and yellow pigments as chlorophyll a, b and beta-carotene. Chlorella has the ability to grow in a wide range of environmental habitats and is able to produce variable hygienic products and hermetical drugs (Kar et al., 2008).

Chlorella is significantly used for remedying cancer, heart and blood vessels diseases. Salinity is one of the most important a biotic stress factor for aquatic organisms, including microalgae (Wang et al., 2008). It induces metabolic alterations in nutrient uptake, accumulation of toxic ions, osmotic stress, and oxidative stress (Verslues et al., 2006). Consequently, salinity results in molecular damage, growth arrest, and causes cell death. Microalgae show great variations in their adaptability response to salinity and other stress conditions. The ability of algal cells to survive and flourish in saline environment under the influence of osmotic stress has received considerable attention (Richmond, 1986). Cells develop many adaptive strategies in response to different a biotic stresses such as salinity, dehydration, cold and excessive osmotic pressure. Algal cells adapt

${ }^{*}$ Corresponding Author: Tel +20 1271179998, email rkebeish@zu.edu.eg, rkebeish@ gmail.com. 
themselves against these stresses by developing different mechanisms including changes in morphological and developmental pattern as well as physiological and biochemical processes (Bohnert et al., 1995). The adaptability of algae to salinity stress is based on their tolerance extent, since they are classified into halophytic (salt requiring for optimum growth) and halo-tolerant (having a mechanism that permits their existence in saline medium). Both algal groups produce some metabolites for their protection from salt injury and for maintaining the surrounding osmotic pressure balance (Richmond, 1986). Stress tolerance is therefore associated with metabolic adjustments that lead to accumulation of several organic solutes and osmolytes.

Various antioxidant enzymes like superoxide dismutase (SOD), Polyphenol oxidase (PPO), peroxidase (POD), and catalase (CAT) are involved in the detoxification of the reactive oxygen species (ROS) in order to avoid algal cell damage induced by salt stress (Cavalcanti et al., 2007). Higher plants also produce compatible solutes like proline or glycine betaine to adjust the osmotic potential within their cell and to serve as osmo-protectants for stabilizing the antioxidative enzymatic activities during osmotic stress (Hasegawa et al., 2000; Hoque et al., 2007). These osmotic adjustments protect sub-cellular structures and reduce oxidative damage caused by free radicals produced in response to high salinity.

Salt stress could have negative effects on photosynthetic mechanism in algae through DNA mutation, transcriptional regulation of some photosynthetic genes, protein denaturation, lipid peroxidation and chlorophyll bleaching (Leshem et al., 2007). The effects of salt stress on phytoplankton have rarely been assessed at the gene transcription level. Therefore, the aim of the current study is to assess the effects of salt stress on pigmentation system, antioxidant enzymes, and photosynthesis related genes expression in the unicellular green alga Chlorella vulgaris. Transcript accumulations of three photosynthesis-related genes were measured under different $\mathrm{NaCl}$ concentrations: $r b c \mathrm{~L}, p s a \mathrm{~B}$, and $p s b \mathrm{C}$. $r b c \mathrm{~L}$ encodes the large subunit of Rubisco, the key enzyme of the Calvin cycle that catalyzes the primary step in $\mathrm{CO}_{2}$ assimilation into organic carbon. $p s a \mathrm{~B}$ is part of the $p s a \mathrm{~A} / \mathrm{B}$ operon of the chloroplast genome and encodes the photosystem I (PSI) reaction center protein. $p s b \mathrm{C}$ encodes an integral membrane protein component of photosystem II (PSII) that plays a major role in transduction of excitation energy from the light harvesting proteins to the photochemical reaction center.

\section{Material and Methods}

\section{Algal culture and $\mathrm{NaCl}$ treatment}

The test organism, Chlorella vulgaris, was obtained from the National Research Center (NRC); Dokki, Giza, Egypt. The alga was cultured in $250 \mathrm{ml}$ flasks containing $100 \mathrm{ml}$ sterilized Bold Basal Medium (Bischoff and Bold, 1963) supplemented with sterile compressed air and kept under fluorescent light

Egypt. J. Bot., 54, No. 2 (2014) 
$\left(50 \mu \mathrm{mol} \mathrm{m} \mathrm{m}^{-2} \mathrm{~s}^{-1}\right)$ with $16 \mathrm{hr}$ light period and at $25^{\circ} \mathrm{C} \pm 2{ }^{\circ} \mathrm{C}$ temperature. Exponential phase of $C$. vulgaris growth was determined in cultures, where it grown for $14 \mathrm{~d}$ in media containing $\mathrm{NaCl}$ at concentrations of 50,150,250, and $300 \mathrm{mM}$. The starting cultures were adjusted to contain $0.125 \times 10^{6}$ cell ml${ }^{-1}$ medium.

Pigment fraction, total free amino acids and proline contents

Chl. a, Chl. b and Carotenoid contents of fresh algal cells was measured by extracting these pigments with $80 \%$ chilled acetone after $14 \mathrm{~d}$ of algal growth under salt stress. The absorbance at 475, 645, and $663 \mathrm{~nm}$ were read in a Spectrophotometer (UV/VIS model T80+, PG Instrument, UK) and the calculation was made according to Arnon (1949). Total free amino acids were determined according to Lee and Takahashi (1966) using glycine as a standard. Extraction and determination of proline was performed according to the method of Bates et al. (1973).

\section{Antioxidative enzymes extraction and assays}

The fresh algal cells were homogenized in cold phosphate buffer $(0.05 \mathrm{M}$ at $\mathrm{pH}$ 7.5). The homogenate was centrifuged at $12000 \mathrm{rpm}$ for 20 minutes at $4^{\circ} \mathrm{C}$ (Kar and Mishra, 1976). The supernatant was used for analyzing the activity of Catalase (CAT) (Xu et al. 2008), Peroxidise (POD), (Racusen and Foote, 1965) Polyphenol oxidase (PPO) (Kar and Mishra, 1976), and Superoxide dismutase (SOD) (Zhang and Zhai, 2003).

RNA was prepared from $50 \mathrm{ml}$ Chlorella vulgaris cell cultures after 2 days exposure to different $\mathrm{NaCl}$ concentrations following the BCP (1-bromo-3chlorpropane) protocol (Chomczynski and Mackey, 1995). Nucleic acid concentrations were measured spectrophotometrically at $260 \mathrm{~nm}$. The 260/280 $\mathrm{nm}$ ratios were determined and referred to as the purity of the total RNA extracted. The integrity was tested by electrophoresis on a $1 \%$ agarose gel. Preparation of first strand cDNA was performed as described by Niessen et al. (2007) where the remaining genomic DNA in the preparation was subjected to DNase digestion before first strand cDNA synthesis. Gene-specific primer pairs of $p s a \mathrm{~B}, p s b \mathrm{C}, r b c \mathrm{~L}$, and housekeeping gene $18 \mathrm{~S}$ rRNA used for PCR are listed in Table 1 . The $18 \mathrm{~S}$ rRNA transcript was used to standardize the results by eliminating variations in the quantity and quality of mRNA and cDNA. Each mRNA level was expressed as the ratio of itself to 18S rRNA. RT-PCR amplifications were performed in the presence of SYBR Green $\left(\mathrm{SYBR}^{\circledR}\right.$ GreenER $^{\mathrm{TM}}$ qPCR SuperMixes; Invitrogen), and oligonucleotides were purchased from Metabion, Planegg, Germany. The final primer concentration was $200 \mathrm{nM}$ in the reaction mixture. Amplification conditions were $10 \mathrm{~min}$ of initial denaturation at $95{ }^{\circ} \mathrm{C}$, followed by 40 cycles each of $15 \mathrm{~s}$ denaturation at $95{ }^{\circ} \mathrm{C}$ and $1 \mathrm{~min}$ combined annealing and extension at $60{ }^{\circ} \mathrm{C}$. 
TABLE 1. Sequence of primer pairs used in real time RT-PCR.

\begin{tabular}{|c|c|c|}
\hline $\begin{array}{l}\text { Gene } \\
\text { name }\end{array}$ & Primer & $\begin{array}{c}\text { GenBank accession } \\
\text { no. }\end{array}$ \\
\hline $\begin{array}{l}\text { 18S } \\
\text { rRNA }\end{array}$ & $\begin{array}{l}\text { Forward 5`- } \\
\text { TTCTATGGGTGGTGGTGCAT-3` } \\
\text { Reverse 5`- } \\
\text { GCGAACCAACCGTGACTATT-3` }\end{array}$ & X13688 \\
\hline$p s a \mathrm{~B}$ & $\begin{array}{l}\text { Forward 5`- } \\
\text { TGCCACTGGGTTTATGTTCC-3 } \\
\text { Reverse 5`- } \\
\text { GCCATCGTACGAGATTTGCT-3` }\end{array}$ & GeneID:809130 \\
\hline$p s b C$ & $\begin{array}{l}\text { Forward 5`- } \\
\text { GAACGTCGTGCTGCTGAATA-3` } \\
\text { Reverse 5`- } \\
\text { CCAACTACGCGGAGAAACAT-3` }\end{array}$ & GeneID:809108 \\
\hline$r b c \mathrm{~L}$ & $\begin{array}{l}\text { Forward 5`- } \\
\text { CGGTGGTGGTACTTTAGTC-3` } \\
\text { Reverse 5`- } \\
\text { TCACGAGCAAGATCACGACC-3` }\end{array}$ & AF499684 \\
\hline
\end{tabular}

psa B: Photosystem I reaction center protein subunit $\mathrm{B}, p s b C$ : Photosystem II reaction center protein subunit $\mathrm{C}$, and $r b c \mathrm{~L}$ : Large subunit of Rubisco.

\section{Statistical analysis}

Data are presented as mean \pm standard error of the mean. Significance was determined according to Student's $t$-test using Excel software (Microsoft). Twosided tests were performed for homoscedastic matrices.

\section{Results and Discussion}

This study was conducted to evaluate the effect of salinity on the growth and biochemical traits of Chlorella vulgaris. For this, the microalga was allowed to grow at different $\mathrm{NaCl}$ concentrations where the effects of salinity on algal growth, pigment fractions, bioactive metabolites, antioxidant enzymes activity, and photosynthesis related gene expression were studied.

Evaluation of Chlorella vulgaris growth under salt stress

The growth of Chlorella vulgaris was measured by estimating the cell density in terms of optical density changes at $678 \mathrm{~nm}$ in presence of different concentrations of $\mathrm{NaCl}$ as shown in Fig. 1. No lag phases for the alga were observed in the first three concentrations of $\mathrm{NaCl}$ (i.e. 50, 150, and $200 \mathrm{mM}$ ) and control culture. This indicating that the alga has good adaptability to these growth conditions. However, the growth patterns of Chlorella vulgaris at 250 and $300 \mathrm{mM} \mathrm{NaCl}$ have lag phases extended for four days then started to be in the exponential phase. Moreover, the exponential phases of Chlorella in the last two concentrations extended for six days then passed to the stationary phase.

Egypt. J. Bot., 54, No. 2 (2014) 
Whereas the control samples started the exponential phase with the inoculums and their overall growth was $\mathrm{NaCl}$ dependent. Thus, the alga before and after primary settling has highly overlapped growth curves along the experiment time. This growth behavior with $\mathrm{NaCl}$ treatment shows a strong relationship between salt stress levels, nutrient levels and algal growth response.

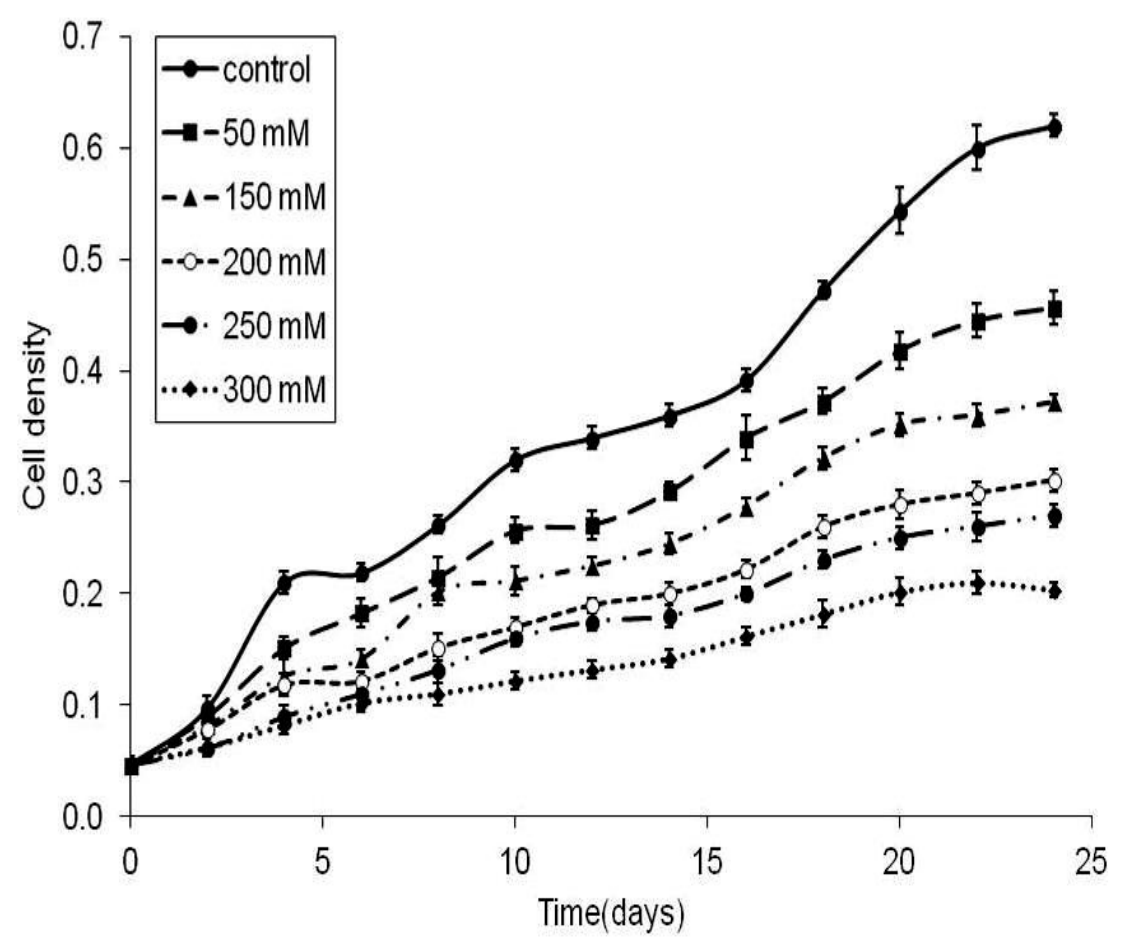

Fig. 1. Effect of salinity on growth of Chlorella vulgaris

Growth response curves of Chlorella vulgaris treated with different concentrations of $\mathbf{N a C l} ; \mathbf{0}$, $50,150,250$, and $300 \mathrm{mM}$. The alga was cultured in $250 \mathrm{ml}$ flasks containing $100 \mathrm{ml}$ sterilized Bold Basal Medium and kept under fluorescent light $\left(50 \mu \mathrm{mol} \mathrm{m}^{-2} \mathrm{~s}^{-1}\right)$ with $16 \mathrm{~h}$ light period at $25 \pm 2{ }^{\circ} \mathrm{C}$. The cell density was determined by measuring the optical density at $678 \mathrm{~nm}$ (Robert, 1979). Vertical bars represent standard error of at least three independent measurements.

Effect of salinity on pigment fractions of C. vulgaris

It was observed that $\mathrm{NaCl}$ treatment enhances the biosynthesis of chlorophyll a; chlorophyll b, and carotenoids to reach its maximum at $200 \mathrm{mM} \mathrm{NaCl}$ as shown in Fig. 2. The percentages of increase were 33 and $78 \%$ for $\mathrm{Chl}$. a, and Chl. b; respectively, when compared to their corresponding control samples. In a similar study, Shaila and Pratima (2010) found that the relatively low salt concentration stimulates chlorophyll biosynthesis in Chlorella vulgaris. However, relatively higher salt concentration reduces chlorophyll contents 
accompanied by a decrease in photosynthetic rate due to osmotic and toxic ionic stress (Moradi and Ismail, 2007). Moreover, Singh and Kshatriya (2002) and Srivastava et al. (2008) reported that salinity induces a clear reduction in the pigmentation and photosynthetic rate in cyanobacteria. However, Musyimi et al. (2007) proposed that chloride ion may play a role in inhibition of chloroplast reactions and the biosynthesis of Rubisco enzyme resulting in accelerating levels of chlorophyll degradation. The reduction of chlorophyll contents may be attributed to the destruction of chlorophyll pigments and the instability of the pigment protein complexes. Fig. 2 shows also $\sim 3$ fold increase in the biosynthesis of carotene compared to its corresponding values in the control samples at relatively moderate concentration of $\mathrm{NaCl}(200 \mathrm{mM})$. These data are in accordance with Pelah et al. (2004). The authors reported that, in the green algae Chlorella zofingiensis, salt stress induced the production of secondary carotenoid astaxanthin. Ranga-Rao et al. (2007) observed 2fold increase in carotenoid content in the green alga Botryococcus braunii treated with $85 \mathrm{mM} \mathrm{NaCl}$. Our observed results showed that the relatively higher concentration of $\mathrm{NaCl}$ supported the biosynthesis of carotenoids rather than chlorophyll a and $\mathrm{b}$. The observed chl.a/chl.b ratio indicates that relatively low and high salt concentrations supported the biosynthesis of chl. b rather than chl. a. However, the ratio of chl.a and chl.b to carotenoids supported the biosynthesis of carotenoids in Chlorella vulgaris following its exposure to relatively higher salt concentration.

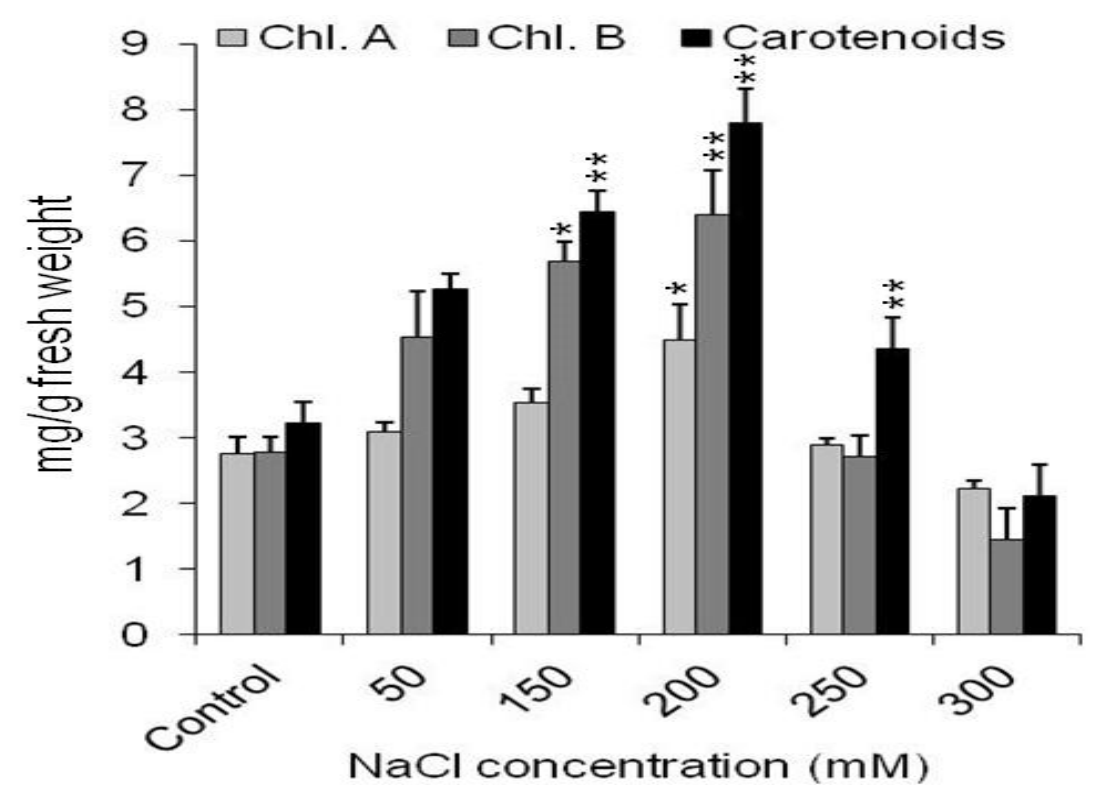

Fig. 2. Effect of $\mathrm{NaCl}$ treatment on pigment contents in Chlorella vulgaris. Vertical bars represent standard error; * $\mathrm{P}<0.05 ;{ }^{* *}, \mathrm{P}<0.01$ according to Student's $t$-test.

Egypt. J. Bot., 54, No. 2 (2014) 
Effect of salinity on free amino acids and proline contents in Chlorella vulgaris

It was obvious that $\mathrm{NaCl}$ treatments increased the accumulation of free amino acids (Fig. 3A) and proline (Fig. 3B) in Chlorella vulgaris at almost all $\mathrm{NaCl}$ concentrations. The maximum amount of both metabolite fractions were observed following the application of 200 and $250 \mathrm{mM}$; respectively. Whereas, the relatively low and moderate concentrations of $\mathrm{NaCl}$ have little stimulatory effects on proline and total free amino acid contents compared to control samples. However, the level of total free amino acids was regularly increased with increasing salt concentration up to $200 \mathrm{mM}$ then this level decreases by increasing salt concentrations. The increased levels of proline and the free amino acids measured in Chlorella under salt stress may be explained on the basis that their accumulation counteract the injury effects induced by salt stress in the algal cells. Our results are in agreement with those obtained by Lin and Kao (1996) who found that the accumulation of free proline and total free amino acids could be one of the major mechanisms of salinity tolerance in some algae.
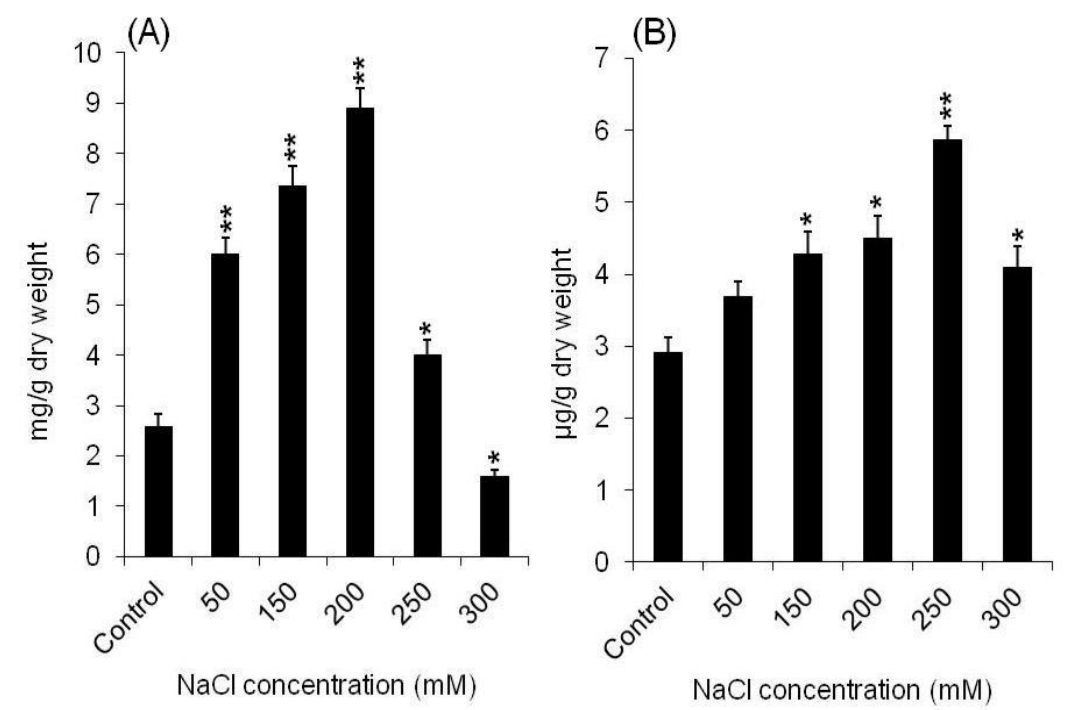

Fig. 3. Effect of $\mathrm{NaCl}$ treatment on total free amino acids (A) and proline contents (B) in Chlorella vulgaris.

Vertical bars represent standard error; *, $\mathrm{P}<0.05 ; * *, \mathrm{P}<0.01$ according to Student's $t$-test.

Effect of salinity on the activity of antioxidant enzymes in C. vulgaris

A dramatic variation in the activity of antioxidant enzymes (Catalyse (CAT), Peroxidase (POD), Polyphenol oxidase (PPO), and Superoxide dismutase (SOD) were observed for $C$. vulgaris under salt stress conditions (Fig. 4). The maximum activities of these antioxidative enzymes were observed at $\mathrm{NaCl}$ concentration of $150 \mathrm{mM}$ especially for Polyphenol oxidase, Peroxidase, and Catalase enzymes. The rate of stimulation was 3, 2, and one-fold increase for PPO, POD, and CAT enzymes; respectively compared to their corresponding controls. Superoxide 
dismutase activity significantly increased with increasing salt stress up to 200 $\mathrm{mM} \mathrm{NaCl}$ where SOD activity was doubled compared to their corresponding values measured from control samples. However, the level of SOD activity is gradually decreased with the increase in salt concentrations. This effect is the same for POD and PPO enzymes at 250 and $300 \mathrm{mM} \mathrm{NaCl}$ treatment (Fig. 4). These results reflect the role of antioxidant enzymes minimizing the passive effects of free radicals accumulation in treated algal cultures. A number of enzymatic and non-enzymatic antioxidative defense systems such as ascorbate peroxidase, and glutathione reductase reduce lipids, proteins and nucleic acids damage caused by oxidative stress (Yoshimura et al., 2000). The activities of some other antioxidant enzymes such as catalase and superoxide dismutase were not altered by extreme salinities (Shaish et al., 1993). Catalase is able to scavenge large quantities of $\mathrm{H}_{2} \mathrm{O}_{2}$, but its location outside the chloroplasts limits its protective action. The activities of peroxidase and superoxide dismutase were enhanced at both relatively low and high concentrations of $\mathrm{NaCl}$ (Fig. 4) These data indicated that the elevation in the antioxidative enzyme activities can be considered as a developed biological response for scavenging the free radicals formed by $\mathrm{NaCl}$ treatment. These results were concomitant with the observations of Abd El-Baky et al. (2004). Algae have developed defense system against photo-oxidative damage by anti-oxidative mechanisms to detoxify and eliminate highly reactive oxygen species. These antioxidant defense systems include antioxidant enzymes like superoxide dismutase (SOD), catalsae (CAT), glutathione reductase (GR) ascorbic peroxidase (APX) and peroxidase (POD) (Rijstenbil, 2002). The author reported that algae accumulated large amount of carotenoids, proline, and $\alpha$-tocopherol for an efficient removal of reactive oxygen species that can inhibit photosynthesis by $50 \%$. The main cellular components susceptible to damage by these ROS are lipids (peroxidation of poly-unsaturated fatty acids in membranes), proteins (denaturation), carbohydrates and nucleic acids (Suzuki and Mittler, 2006). Antioxidant defense system is essential for ROS detoxification during normal metabolism and particularly during stress (Suzuki and Mittler, 2006). In the present study, $\mathrm{NaCl}$ exposure enhances the activity of SOD, POD and CAT. SOD is the first step in removal of ROS. Specifically, it converts $\mathrm{O}_{2}{ }^{-}$to $\mathrm{H}_{2} \mathrm{O}_{2}$ and oxygen. Therefore, the increase in the activity of SOD in response to $\mathrm{NaCl}$ application suggests an increased production of $\mathrm{O}_{2}^{-}$. Similarly, the increased activities of POD and CAT indicate potential protection against oxidation by these antioxidant enzymes. Taken together, the induction of these antioxidant enzymes in Chlorella vulgaris at moderate and high salt concentrations reflects the adaptability of this microalga to survive in high salt concentrations by triggering the increased levels of reactive oxygen species (ROS).

Egypt. J. Bot., 54, No. 2 (2014) 


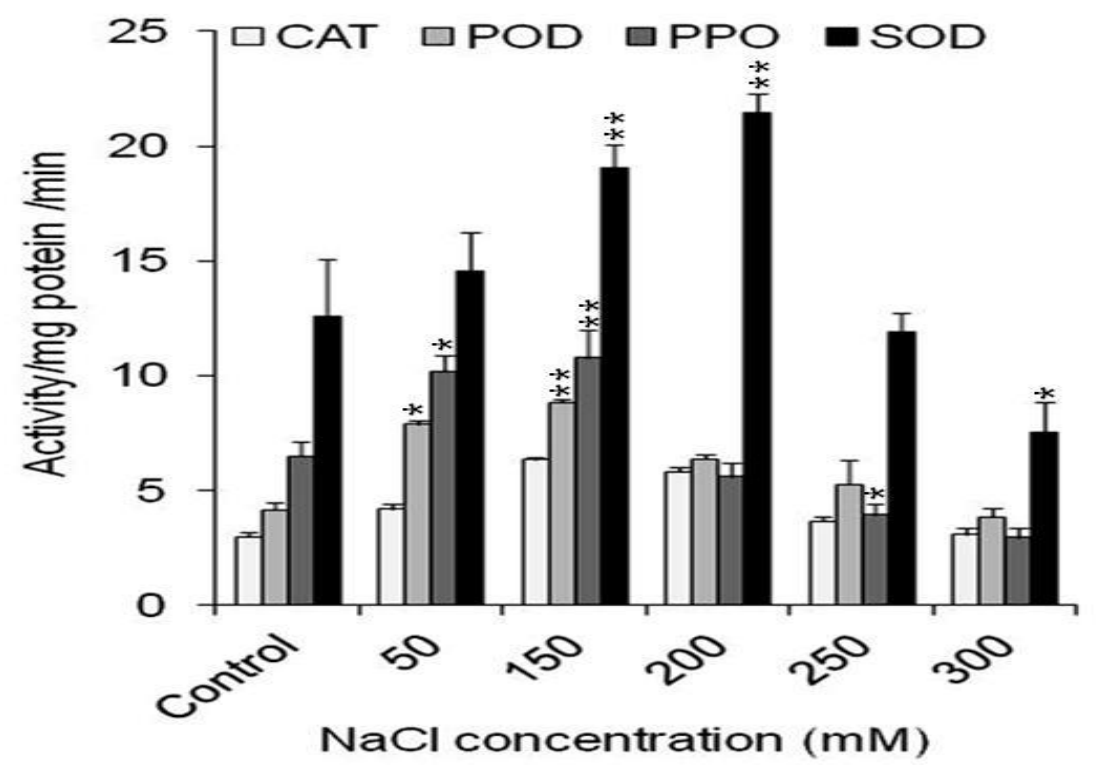

Fig. 4. Effect of $\mathrm{NaCl}$ treatment on the activity of antioxidant enzymes; Catalase (CAT), Peroxidise (POD), Polyphenol oxidase (PPO), and Superoxide dismutase (SOD) in Chlorella vulgaris.

Vertical bars represent standard error. $(*)$ and $(* *)$ represent statistically significant differences when compared with control samples at $p<0.05$ and at $p<0.01$ levels, respectively.

Effect of salinity on photosynthetic gene expression

The relative transcript abundances of three photosynthesis related gene transcripts, $p s a \mathrm{~B}, p s b \mathrm{C}$ and $r b c \mathrm{~L}$ genes, was measured in $C$. vulgaris after two days of exposure to different $\mathrm{NaCl}$ concentrations (Fig. 5) Abundance of $r b c \mathrm{~L}$ transcripts was significantly affected by $\mathrm{NaCl}$ treatments at concentrations of 200, 250, and $300 \mathrm{mM}$ (Fig. 5). After two days of exposure, the abundance of $r b c \mathrm{~L}$ transcripts was reduced by $\sim 42 \%$ compared to the corresponding values measured from the control samples at 250 and $300 \mathrm{mM} \mathrm{NaCl}$. The abundance of $p s a \mathrm{~B}$ transcript was also decreased upon $\mathrm{NaCl}$ exposure. For example, the minimum transcript abundance after $48 \mathrm{hr}$ of exposure was reached at $250 \mathrm{mM}$ $\mathrm{NaCl}$ concentration with a reduction of $45 \%$ compared to the corresponding control samples. $p s b C$ exhibited different responses to $\mathrm{NaCl}$ treatment (Fig. 5). At moderate and high $\mathrm{NaCl}$ concentrations, abundance of the $p s b \mathrm{C}$ transcript was significantly decreased compared to control samples. In fact, $\mathrm{NaCl}$ concentrations of $150,200,250$, and $300 \mathrm{mM}$ resulted in a $35-55 \%$ decrease in $p s b \mathrm{C}$ transcript abundance as compared to the control sample. The maximum decrease in $p s b \mathrm{C}$ transcript abundance was observed after $48 \mathrm{hr}$ exposure to 300 $\mathrm{mM}$ of $\mathrm{NaCl}$. These results clearly show the strong influence of salt stress on the transcription of photosynthetic genes. These results are in accordance with that observed by Qian et al. (2009) and Qian et al. (2008a). The authors observed 
a decrease in $r b c \mathrm{~L}, p s a \mathrm{~B}$, and $p s b \mathrm{C}$ gene transcripts upon exposure to different concentrations of copper and cadmium, separately and in combinations. Moreover, exposure of Chlorella vulgaris to variable concentrations of glufosinate induces a great reduction in these photosynthetic related gene transcripts. The decrease in transcript abundance resulted in a decrease in the amount of corresponding enzyme and its activity. Rubisco has both carboxylase and oxygenase activities that control the rate-limiting step of carbon assimilation and photorespiration, respectively. By decreasing the abundance of $r b c \mathrm{~L}$ and blocking carbon assimilation and photorespiration, $\mathrm{NaCl}$ causes the accumulation of a mass of reducing equivalents. Excess electrons can lead to decreased transcription of PSI and PSII genes. This, in turn, reduces electron flow through PSI and PSII (Qian et al., 2008a). In this study we observed a decrease in the photosynthesis-related genes, $p s b \mathrm{C}$ and $p s a \mathrm{~B}$. Electron transport occurs at PSII first, and then is relayed to PSI. Thus, the inhibition of electron transport first occurred in PSII, because the transcript abundance of $p s b \mathrm{C}$ and psa $\mathrm{B}$ decreased after 2 days of $\mathrm{NaCl}$ exposure. When electron transport is blocked at PSII, algal cells tend to increase related protein at PSI to enhance electron receptivity from PSII. This strategy may enable photosynthesis to proceed as normally as possible, especially under adverse conditions (Pfannschmidt, 2003). When the salt stress pressures exceed the organism's ability to tolerate the stress, normal metabolism is inevitably disrupted, resulting in subsequent decrease in the transcript abundance of both $p s a \mathrm{~B}$ and $p s b \mathrm{C}$. It was also shown that these photosynthesis genes were regulated at transcript level upon atrazine exposure (Qian et al., 2008b). Taken together, salinity stress conditions and its impediment to energy conversion decreases the photosynthetic related gene transcripts and also increases the accumulation of $\mathrm{O}_{2}^{-}$and peroxidation of membrane lipids which probably results in the destruction of chloroplast.

\section{Conclusion}

The results from this study suggest that $\mathrm{NaCl}$ treatment alters photosynthetic gene transcription, and physiological state of $C$. vulgaris. It is clearly shown that $\mathrm{NaCl}$ not only changes antioxidant enzyme activities and pigment fractions but also has negative effects on the transcriptional abundance of photosynthesis related genes thereby reducing the PSII efficiency and the overall $\mathrm{CO}_{2}$ assimilation rates.

Acknowledgements:This study was supported partly by the Botany Department, Faculty of Science, Zagazig University. Many thanks to Mr. Emad Hamdy, Botany Department, Faculty of Science, Zagazig University, for his great help with RNA isolation, cDNA synthesis, and RT-PCR analysis. 


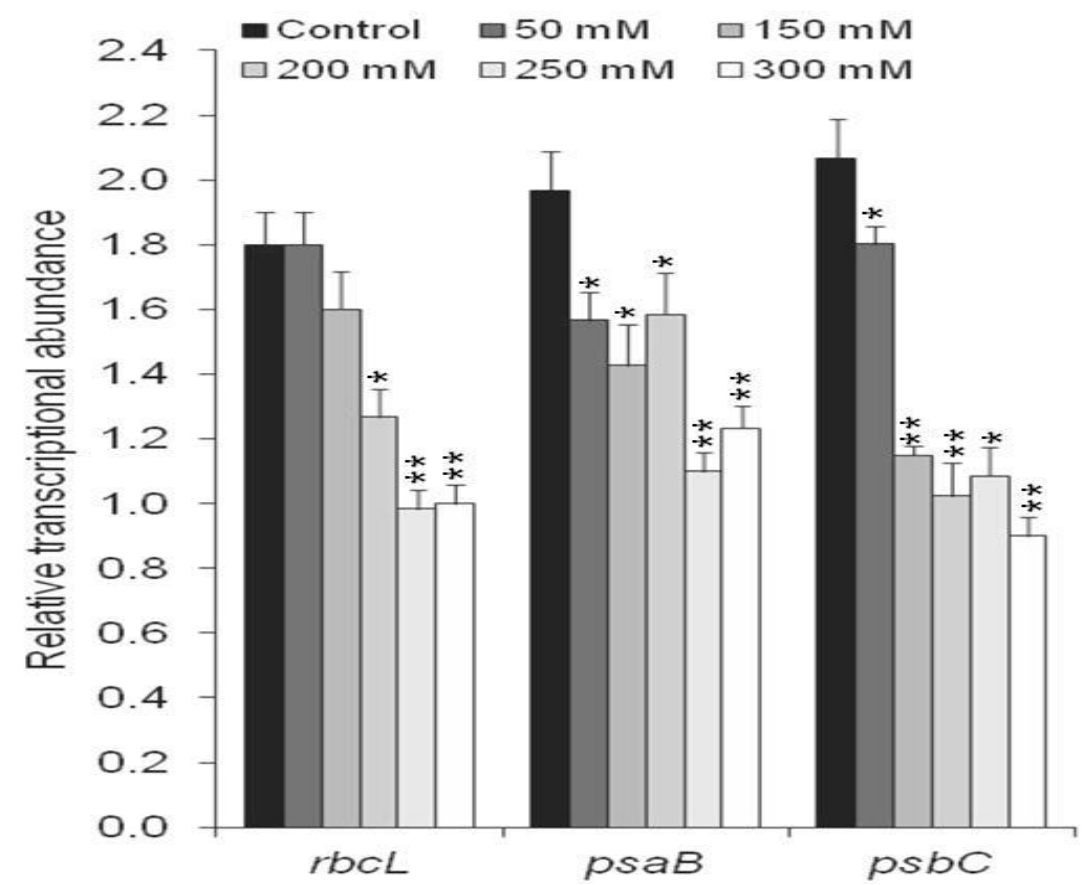

Fig. 5. Real time RT-PCR anaylsis of mRNA transcripts of $r b c \mathrm{~L}, p s a \mathrm{~B}$, and $p s b \mathrm{C}$ in Chlorella vulgaris upon exposure to different $\mathrm{NaCl}$ concentrations.

Transcripts of large subunit of Rubisco $(r b c \mathrm{~L})$, photosystem I reaction center protein subunits B (psaB), and an integral membrane protein component of photosystem II (psbC) in Chlorella vulgaris exposed to varying concentrations of $\mathrm{NaCl} ; 0,50,150,250$, and $300 \mathrm{mM}$. Algae were cultured at $25 \pm 2{ }^{\circ} \mathrm{C}, 50 \mu \mathrm{mol} \mathrm{m} \mathrm{m}^{-2} \mathrm{~s}^{-1}$ and 16:8 h L/D cycle. Salt treatment was performed at the logarithmic growth phase of Chlorella $(10 \mathrm{~d}$ of growth) and the measurements were performed 2 days after salt application. Values were normalized against $18 \mathrm{~S}$ rRNA for each treatment. Each data point is based on at least three independent RNA preparations. Error bars indicate s.e.m.; *, $\mathrm{P}<0.05$; **, $\mathrm{P}<0.01$ according to Student's $t$-test.

\section{References}

Abd El-Baky, H.H., El baz, F. K. and El-baroty, G. S. (2004) Production of Antioxidant by the Green Alga Dunaliella salina. . Int. J. Agri. Biol., 6, 49-57.

Arnon, D.I. (1949) Copper enzymes in isolated chloroplasts: Polyphenoloxidase in Beta vulgaris. Plant Physiol., 24, 1-15.

Bates, L.S., Walds, R.P., and Teare, I.D. (1973) 1973. Rapid determination of free proline for water stress studies. Plant and Soil, 39, 205-207.

Bischoff, H.W. and Bold, H.C. (1963) Phycological studies. 4- Some soil algae from Enchanted rock and related algal species. Univ. Texas. Publ., 6318, 32-36. 
Bohnert, H.J., Nelson, D.E. and Jensen, R.G. (1995) Adaptations to environmental stresses. Plant Cell Physiol., 7, 1099-1111.

Britton, G., Liaaen-Jensen, S. and Pfander, H. (1995) "Carotenoids. Birkhauser Verlag", Basel, Switzerland, 1, 13-63.

Cavalcanti, F. R., Lima, J., Ferreira-Silva, S. L., Viégas, R. A. and Silveira, J. (2007) Roots and leaves display contrasting oxidative response during salt stress and recovery in cow pea. . Journal of Plant Physiology, 164, 591-600.

Chomczynski, P. and Mackey, K. (1995) Substitution of chloroform by bromochloropropane in the single-step method of RNA isolation. Anal. Biochem., 225, 163164.

Hasegawa, P.M., Bressan, R.A., Zhu, J.K., and Bohnert, H.J. (2000) Plant cellular and molecular responses to high salinity. Annual Review of Plant Physiology and Plant Molecular Biology., 51, 463-499.

Hoque, M.A., Okuma, E., Banu, M.N.A., Nakamura, Y., Shimoishi, Y., and Murata, Y. (2007) Exogenous proline mitigates the detrimental effects of salt stress more than the betaine by increasing antioxidant enzyme activities. J. Plant Physiol., 164, 553561.

Kar, D., Sur, P., Mandal, S. K., Saha, T. and Kole, R. K. (2008) Assessment of heavy metal pollution in surface water. International Journal of Environ. Sciences Technology. 5, 119-124.

Kar, M. and Mishra, D. (1976) Catalase, peroxidase, polyphenol oxidase activities during rice leaf senescence. Plant Physiol., 57, 315-319.

Lee, Y.P. and Takahashi, T. (1966) Spectrophotometric Determination of Amino Acids with Ninhydrin. Anal. Biochem., 14, 71-77.

Leshem, Y., Seri, L. and Levine, A. (2007) Induction of phosphatidylinositol 3-kinasemediated endocytosis by salt stress leads to intracellular production of reactive oxygen species and salt tolerance. The Plant Journal., 51, 185-197.

Lin, C.C. and Kao, C.H. (1996) Proline accumulation is associated with inhibition of rice seedlings root growth caused by $\mathrm{NaCl}$. Plant Sci., 114, 121-128.

Moradi, M. and Ismail, A.M (2007) Responses of photosynthesis, chlorophyll fluorescence and ROS - scavenging systems to salt stress during seedling and reproductive stages of Rice. Anal. Botany, 99, 1161-1173.

Musyimi, D.M., Netondo, G.W. and Ouma, G. (2007) Effect of salinity on growth and photosynthesis of avocado seedling. Int. J. Bot., 3, 78-84.

Niessen, M., Thiruveedhi, K., Rosenkranz, R., Kebeish, R., Hirsch, H.-J., Kreuzaler, F. and Peterhansel, C. (2007) Mitochondrial glycolate oxidation contributes to photorespiration in higher plants. J. Exp. Bot., 58, 2709-2715.

Egypt. J. Bot., 54, No. 2 (2014) 
Pelah, D., Sintov, A. and Cohen, E. (2004) The effect of salt stress on the production of canthaxanthin and astaxanthin by Chlorella zofingiensis grown under limited light intensity. World Journal of Microbiology and Biotechnology, 20, 483-486.

Pfannschmidt, T. (2003) Chloroplast redox signals: how photosynthesis controls its own genes. Trends Plant Sci., 8, 33-41.

Qian, H.F., Chen, W., Sheng, G.D., Liu, W.P. and Fu, Z.W. (2009) Combined effect of copper and cadmium on Chlorella vulgaris growth and photosynthesis-related gene transcription. Aquatic Toxicology, 94, 56-61.

Qian, H.F., Chen, W., Sheng, G.D., Xu, X.Y., Liu, W.P. and Fu, Z.W. (2008a) Effects of glufosinate on antioxidant enzymes, subcellular structure, and gene expression in the unicellular green alga Chlorella vulgaris. Aquat. Toxicol., 88, 301-307.

Qian, H.F., Sheng, G.D., Liu, W.P., Lu, Y.C., Liu, Z.H. and Fu, Z.W. (2008b) Inhibitory effects of atrazine on Chlorella vulgaris as assessed by real-time polymerase chain reaction. Environ. Toxicol., Chem. 27, 190-195.

Racusen, D. and Foote, M. (1965) Protein synthesis in dark grown bean leaves. Can. J. Bot., 43, 817-824.

Ranga-Rao, A., Dayanada, C., Sarada, R., Shamala, T. R. and Ravishankar, G.A. (2007) Effect of salinity on growth of green alga Botryococcus braunii and its constituents. Bioresource Technology, 98, 560-564.

Richmond, A. (1986) Cell response to environmental factors. Richmond, A. (Ed.), CRC In: "Handbook of Microalgal Mass culture". CRC Press Inc., Florida, pp. 89-95.

Rijstenbil, J.W. (2002) Assessment of oxidative stress in the planktonic diatom Thalassiosira pseudonana in response to UV-A and UV-B radiation. J. Plankton Res., 12, 1277-88.

Robert, R.L.G. (1979) Growth measurements. Division rate. In: "Physiological Methods. Culture and Growth Measurements". R.J. Stein (Ed.), Cambridge University Press, Cambridge. p.275.

Shaila, H. and Pratima, M. (2010) Impact of Salinity on the Physiological and Biochemical Traits of Chlorella vulgaris Beijerinck. J. Algal Biomass Utln., 1, 51-59.

Shaish, A., Avron, M., Pick, U. and Ben-Amotz, A. (1993) Are active oxygen species involved in induction of b-carotene in Dunaliella bardawil? . Planta, 190, 363-368.

Singh, D.P. and Kshatriya, K. (2002) NaCl-induced oxidative damage in the cyanobacterium Anabaena doliolum. Curr. Microbiol., 44, 411-417

Srivastava, A.K., Bhargava, P., hapar, R. and Rai, L.C. (2008) Salinity induced physiological and proteomic changes in Anabaena doliolum. Environ. Exp. Bot., 64, 49- 57.

Suzuki, N. and Mittler, R. (2006) Reactive oxygen species and temperature stresses: A delicate balance between signaling and destruction Physiol. Plantarum., 126, 45-51.

Egypt. J. Bot., 54, No. 2 (2014) 
Takaichi, S. (2011) Carotenoids in Algae: Distributions, Biosyntheses and Functions. Marine Drugs, 9, 1101-1118.

Verslues, P.E., Agarwal, M., Katiyar-Agarwal, S., Zhu, J. and Zhu, J. K. (2006) Methods and concepts in quantifying resistance to drought, salt and freezing, abiotic stresses that affect plant water status. Plant J., 45, 523-539.

Wang, R., Chen, S., Zhou, X., Shen, X., Deng, L., Zhu, H., Shao, J., Shi, Y., Dai, S., Fritz, E. (2008) Ionic homeostasis and reactive oxygen species control in leaves and xylem sap of two poplars subjected to $\mathrm{NaCl}$ stress. Tree Physiol., 28, 947-957.

Xu, P., Zou, J., Meng, Q., Zou, J., Jiang, W. and Liu, D. (2008) Effect of Cd2+ on seedling growth of garlic (Allium sativum L.) and selected physiological and biochemical characters. Bioreseource Technology., 99, 6372-78.

Yoshimura, K., Yabuta, Y., Ishikawa, T. and Shigeoka, S. (2000) Expression of spinach ascorbate peroxidase isoenzymes in response to oxidative stresses Plant Physiol., 123, 223.

Zhang, Z.L. and Zhai, W.Q. (2003) The Experimental Guide for Plant Physiology, $3^{\text {rd }}$ ed., Higher Education Press. Beijing, China. 123-274.

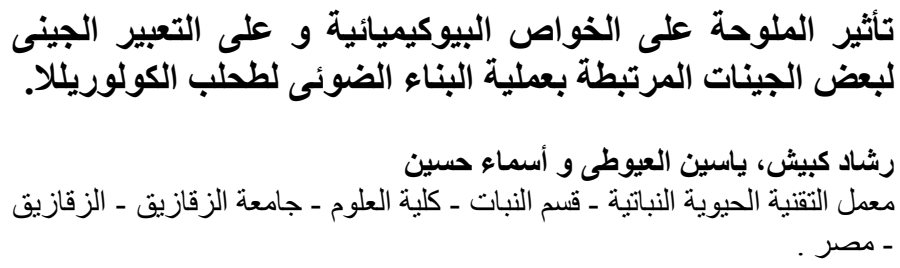

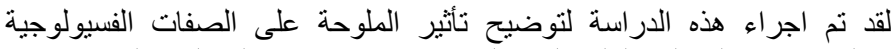

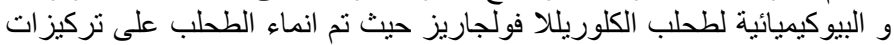

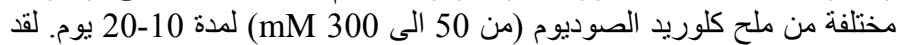

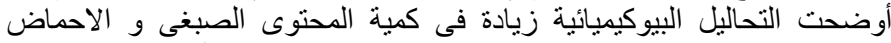

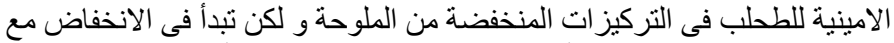

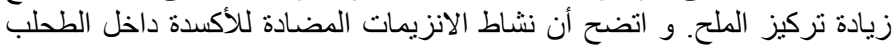

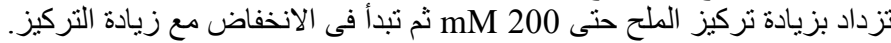

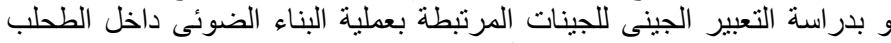

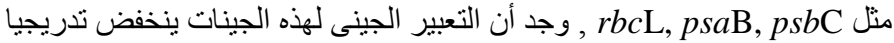

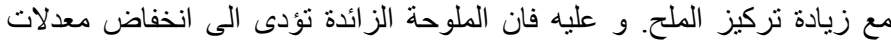
التمثيل الضوئى داخل طحلب الكلوريلا فيل فولحاريز. 